\title{
Prognostic Value of RV Tissue Annular Velocity in Chronic Pulmonary Artery Hypertension
}

\author{
Prabin Shrivastava, Pravin Kumar Jha, Tony Ete, Swapan Saha, Rinchin Dorjee Megeji, Gaurav \\ Kavi, Chandra Kumar Das, Shingamlung Kamei, Dhanjit Nath, Synrang Batngen Warjri, Rondeep \\ Kumar Sivam, Manish Kapoor, Amit Malviya, Animesh Mishra*
}

Department of Cardiology, North Eastern Indira Gandhi Regional Institute of Health and Medical Sciences, Shillong, India Email: ${ }^{\star d r a n i m e s h m s h i l l o n g @ g m a i l . c o m ~}$

How to cite this paper: Shrivastava, P., Jha, P.K., Ete, T., Saha, S., Megeji, R.D., Kavi, G., Das, C.K., Kamei, S., Nath, D., Warjri, S.B., Sivam, R.K., Kapoor, M., Malviya, A. and Mishra, A. (2017) Prognostic Value of RV Tissue Annular Velocity in Chronic Pulmonary Artery Hypertension. Open Access Library Journal, 4: e3295.

https://doi.org/10.4236/oalib.1103295

Received: April 2, 2017

Accepted: May 15, 2017

Published: May 18, 2017

Copyright (๑) 2017 by authors and Open Access Library Inc.

This work is licensed under the Creative Commons Attribution International License (CC BY 4.0).

http://creativecommons.org/licenses/by/4.0/

\begin{abstract}
Background: Elevated afterload in chronic pulmonary artery hypertension (PAH) leads to sequence of events resulting in right ventricular (RV) hypertrophy, dilatation and eventual RV dysfunction. In last two decades, great emphasis has been laid on the right ventricular function for the prognosis of $\mathrm{PAH}$. Hence, RV functional assessment is essential for assessing prognosis and monitoring therapeutic interventions in PAH patient. The purpose of this study to evaluate the prognostic value of pulse wave tissue Doppler imaging (PW-TDI) in chronic PAH patients. Methods: Eighty five patients (85) with chronic pulmonary artery hypertension were analysed. Patients were divided into two groups according to pulmonary artery systolic pressure by 2-D echocardiography as follows: group A $(\mathrm{n}=56)$ included mild to moderate PAH with pulmonary artery systolic pressure less than $70 \mathrm{~mm}$ of mercury and group $B(n=29)$ included severe pulmonary artery pressure with pulmonary artery systolic pressure of more than equal to $70 \mathrm{~mm}$ of mercury. RV dysfunction was present in $8.9 \%(n=5) \& 24.1 \%(n=7)$ of patients in group A and B respectively $(\mathrm{p}=0.01)$. Tricuspid annulus plain systolic excursion (TAPSE) was measured at tricuspid annulus in $\mathrm{M}$ mode and pulse wave tissue Doppler imaging (PW-TDI) was performed and early diastolic annular velocities were recorded at the septal and lateral tricuspid annulus in all patients. Patients were followed for six months. Results: The present study demonstrates an inverse correlation between right ventricular (RV) performance indices e.g., TAPSE, RVPW-TDI early diastolic annular velocity (E') and systolic pulmonary artery pressure in both groups of PAH patients. TAPSE was $20.45 \mathrm{~mm}$ and $18.13 \mathrm{~mm}$ $(\mathrm{p}<0.05)$ whereas $\mathrm{E}^{\prime}$ lateral annular velocity was $16.05 \mathrm{~cm} / \mathrm{sec}$ and 13.33 $\mathrm{cm} / \mathrm{sec}(\mathrm{p}<0.05)$ for group A and B patients respectively. Similarly, TAPSE was $15.9 \mathrm{~mm}$ and $10.2 \mathrm{~mm}(\mathrm{p}<0.05)$ whereas $\mathrm{E}^{\prime}$ lateral annular velocity was 20.6 $\mathrm{cm} / \mathrm{sec}$ and $13.6 \mathrm{~cm} / \mathrm{sec}(\mathrm{p}<0.05)$ for normal RV function and RV dysfunction patients respectively. Lower TAPSE and RV TDI early diastolic annular veloci-
\end{abstract}


ties had more re-hospitalization ( $\mathrm{p}<0.05)$. Conclusion: The measurement of TAPSE by M-mode and RV TDI early diastolic annular velocities is a non-invasive, effective, simple and reproducible method that correlated well with pulmonary artery systolic pressure (PASP) and right ventricular function.

\section{Subject Areas}

Cardiology

\section{Keywords}

Pulmonary Artery Hypertension, Right Ventricle, Doppler Imaging

\section{Introduction}

Pulmonary artery hypertension (PAH) refers commonly to elevation of pulmonary artery pressures (PAP) above normal, and is defined as having a mean PAP of greater than or equal to $25 \mathrm{mmHg}$. $\mathrm{PAH}$ is present in a number of conditions, e.g. chronic obstructive pulmonary disease, and pulmonary embolism. It may also reflect the presence of underlying pulmonary vascular disease or the presence of elevated pressures in the left heart. Chronically elevated afterload in the form of elevated pulmonary artery pressure leads to sequence of events, subsequently leading to right ventricular (RV) hypertrophy and dysfunction. Symptoms and prognosis in $\mathrm{PAH}$ patients are closely related to right ventricle function. Thus, assessment of right ventricular function is essential for assessing prognosis and monitoring therapeutic interventions in pulmonary hypertension, as RV failure is a major determinant of poor outcomes [1]. Significant advances have been made in this field in the last decade both in the understanding of the pathophysiology and the treatment of pulmonary artery hypertensive patients. Echocardiography is the most commonly used imaging modalities for routine clinical evaluation as it is simple and non-invasive. However, because of the complex geometry of the right ventricle and suboptimal acoustic window, adequate characterization is difficult by echocardiographic techniques. There are different kinds of non-invasive methods to determine pulmonary artery pressure, RV function, and effect of pulmonary artery hypertension on the RV function. However, the effect of chronic elevations in pulmonary artery systolic pressure on diastolic tissue annular velocities has not been well characterized.

\section{Methods}

\section{Study population:}

A total of 85 subjects were enrolled for the study at the department of cardiology, North Eastern Indra Gandhi Regional Institute of Health and Medical Sciences, Meghalaya, India from October 2013 to September 2014. Inclusion criteria were confirmed cases of chronic pulmonary hypertension (both primary and secondary) on basis of echocardiogram. 
Patient with acute pulmonary embolism, acute pulmonary hypertension, and with inadequate Doppler signal were not recruited for the study.

A detailed history, clinical examination and routine blood investigation was done in every case. Participation of all subjects was voluntary and written informed consent was obtained from each subject. This study has been approved by institutional review committee and institute medical ethical committee.

Patients were divided in two groups A and B on the basis of elevated pulmonary artery systolic pressure level. Group A consisted of mild to moderate pulmonary artery hypertensive (PAH) patients with pulmonary artery systolic pressure (PASP) less than $70 \mathrm{~mm}$ of mercury whereas group B consisted of severe $\mathrm{PAH}$ patients with pulmonary artery systolic pressure more than or equal to $70 \mathrm{~mm}$ of mercury. Mild, moderate and severe PAH were classified as pulmonary artery systolic pressure less than $50 \mathrm{mmHg}, 50 \mathrm{mmHg}$ to less than 70 $\mathrm{mmHg}$ and greater than or equal to $70 \mathrm{mmHg}$. RV performance indices e.g., TAPSE and TDI early diastolic annular velocities (E') were compared in both groups. Patients were followed up for 6 months.

\section{Echocardiography.}

Standard two-dimensional (2-D) and Doppler transthoracic echocardiographic (TTE) studies were performed using the Esoate machine. All 2-D and Doppler images were acquired and recorded digitally, and analysed offline.

Tricuspid annular plain systolic excursion (TAPSE) at tricuspid annulus in M mode and PW-TDI early diastolic tissue velocity at lateral tricuspid and septal annulus were acquired. All pulsed Doppler tissue imaging parameters were measured on 5 - 8 consecutive heart cycles. The maximal TR velocity was recorded by continuous-wave Doppler from any standard views that yielded the highest peak velocity during end expiration. The right ventricle-to-right atrium peak pressure gradient $\left(\Delta \mathrm{P}_{\mathrm{RV}-\mathrm{RA}}\right)$ was calculated using the modified Bernoulli equation, $\triangle P(R V-R A)=4 V^{2}$, where $V$ is the peak regurgitant velocity. PASP was estimated by using the equation $\mathrm{PASP}=\Delta \mathrm{P}_{\mathrm{RV}-\mathrm{RA}}+\mathrm{RAP}$, where RAP is the right atrial pressure and was inferred from the inferior vena cava diameter (IVCd) and the caval respiratory index (IVCd during inspiration/IVCd during expiration).

Outcomes and follow up:

End point of the study was comparison of right ventricular (RV) performance indices (TAPSE in M mode and TDI early diastolic annular velocity (E') at septal and lateral tricuspid annulus) with the elevated pulmonary artery systolic pressure (PASP), RV function and re-hospitalization.

\section{Statistical Analysis:}

Clinical and echocardiographic data were expressed as mean for continuous variables or as a number (percent) for categorical variables. Mean of the variables and significance ( $\mathrm{p}$-value) of the study among the groups were analysed by two sample t-test and Z-test respectively using SPSS software. A p $<0.05$ was regarded as statistically significant.

\section{Results}

Eighty five patients were enrolled for the present study. Etiology of the PAH is as 
shown in Table 1. Secondary cause of PAH especially rheumatic heart disease (35.29\%) and congenital heart disease (28.23\%) with shunt physiology were the common in both group with no significant difference $(p=0.47)$.

The patients' characteristics and echocardiographic data for investigational study are depicted in Table 2. Majority (60\%) were females in both groups with no significant difference $(\mathrm{p}=0.12)$. Hypertension and diabetes was prevalent in one-fourth of patients with no difference among groups $(p=0.28)$. Baseline echocardiography was similar in both groups except for significant difference in pseudonormal mitral inflow pattern, TAPSE, early diastolic tricuspid annulus

Table 1. Etiology of PAH.

\begin{tabular}{cccc}
\hline & Total $(\mathrm{N}=85)$ & Group A (N = 56) & Group B (N =29) \\
\hline Idiopathic PAH & $1(1.17 \%)$ & 0 & $1(3.4 \%)$ \\
Rheumatic heart disease & $30(35.29 \%)$ & $20(35.71 \%)$ & $10(34.48 \%)$ \\
Congenital heart disease & $24(28.23 \%)$ & $14(25 \%)$ & $10(34.48 \%)$ \\
COPD & $10(11.76 \%)$ & $5(8.9 \%)$ & $5(17.24 \%)$ \\
Cardiomyopathy & $7(8.23 \%)$ & $4(7.14 \%)$ & $3(10.34 \%)$ \\
Miscellaneous & $13(15.29 \%)$ & $8(14.28 \%)$ & $5(17.24 \%)$ \\
\hline
\end{tabular}

Table 2. Baseline characteristic of patients.

\begin{tabular}{|c|c|c|c|}
\hline & $\begin{array}{c}\text { Group } \mathrm{A}(\mathrm{N}=56) \\
(\mathrm{PASP}<70 \mathrm{mmHg})\end{array}$ & $\begin{array}{c}\text { Group B }(\mathrm{N}=29) \\
(\mathrm{PASP} \geq 70 \mathrm{mmHg})\end{array}$ & $\mathrm{p}$-value \\
\hline Male & $25(44.64 \%)$ & $9(31.03 \%)$ & 0.12 \\
\hline Female & $30(53.57 \%)$ & $20(68.97 \%)$ & 0.12 \\
\hline Systemic hypertension & $15(26.78 \%)$ & $6(20.68 \%)$ & 0.28 \\
\hline Diabetes mellitus & $16(26.78 \%)$ & $4(13.79 \%)$ & 0.07 \\
\hline Smoker & $9(16.07 \%)$ & $5(17.24 \%)$ & 0.43 \\
\hline \multicolumn{4}{|l|}{ MIP } \\
\hline -Normal & $24(42.85 \%)$ & $10(34.48 \%)$ & 0.20 \\
\hline -Grade I diastolic dysfunction & $25(44.64 \%)$ & $10(34.48 \%)$ & 0.20 \\
\hline -Pseudo-normal & $5(8.92 \%)$ & $7(24.13 \%)$ & 0.02 \\
\hline -Restrictive & $2(3.5 \%)$ & $2(6.89 \%)$ & 0.24 \\
\hline TAPSE mm & $\begin{array}{c}20.45 \\
\text { (Mild PAH-20.55 } \\
\text { Moderate PAH-20.41) }\end{array}$ & 18.13 & 0.01 \\
\hline E'Septal mean $(\mathrm{cm} / \mathrm{sec})$ & $\begin{array}{c}12.77 \\
\text { (Mild PAH-13 } \\
\text { Moderate PAH-12.68) }\end{array}$ & 10.26 & 0.10 \\
\hline$E^{\prime}$ Tricuspid Lateral $(\mathrm{cm} / \mathrm{sec})$ & $\begin{array}{c}16.05 \\
\text { (Mild PAH-16.33 } \\
\text { Moderate PAH-15.92) }\end{array}$ & 13.33 & 0.05 \\
\hline \multicolumn{4}{|l|}{ RV function } \\
\hline -Normal & $51(91.07 \%)$ & $22(75.86 \%)$ & 0.02 \\
\hline -RV dysfunction & $5(8.92 \%)$ & $7(24.13 \%)$ & 0.01 \\
\hline \multicolumn{4}{|l|}{ LV function } \\
\hline -Normal LVEF & $39(69.64 \%)$ & $18(62.06 \%)$ & NS \\
\hline -LV dysfunction & $16(28.57 \%)$ & $11(37.93 \%)$ & NS \\
\hline
\end{tabular}


velocity ( $E^{\prime}$ lateral) and RV function status $(\mathrm{p}<0.05)$. The value of early diastolic velocities and TAPSE in mild, moderate and severe pulmonary artery hypertensive patients was inversely related to the level of pulmonary artery systolic pressure.

There was no significant difference in the mean early diastolic annular velocities ( $E^{\prime}$ septal $\mathrm{p}=0.49$; $\mathrm{E}^{\prime}$ lateral $\left.\mathrm{p}=0.47\right)$ and TAPSE $(\mathrm{p}=0.45)$ in group A and B during follow up (Figure 1(a) \& Figure 1(b)).

In patients having RV dysfunction, both early lateral tricuspid annular velocity and TAPSE were significantly different $(\mathrm{p}<0.05)$ at admission and follow up as shown in Table 3.

Re-hospitalized patients had lower RV TDI annular velocity and TAPSE in both groups as depicted in Figure 2(a) \& Figure 2(b), with significant difference $(\mathrm{p}<0.05)$ in the mean RV TDI early diastolic annular velocities and TAPSE between re-hospitalized and non-hospitalized patients in both groups. In group A, two patients were re-hospitalized, both had RV dysfunction where as in group B among seven re-hospitalized patients, four had RV dysfunction.

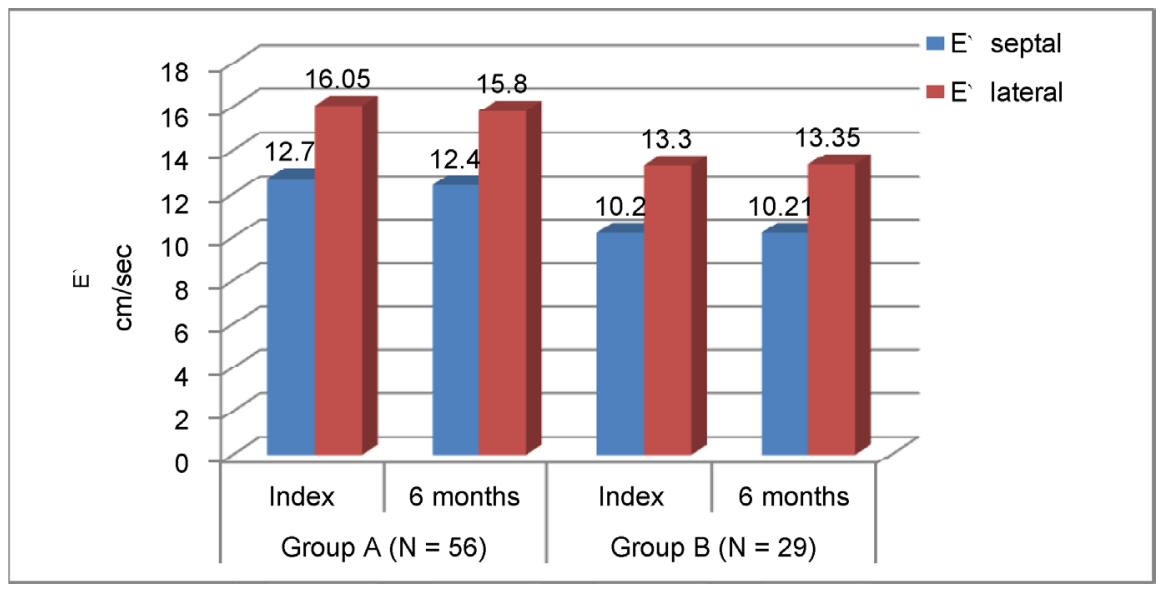

(a)

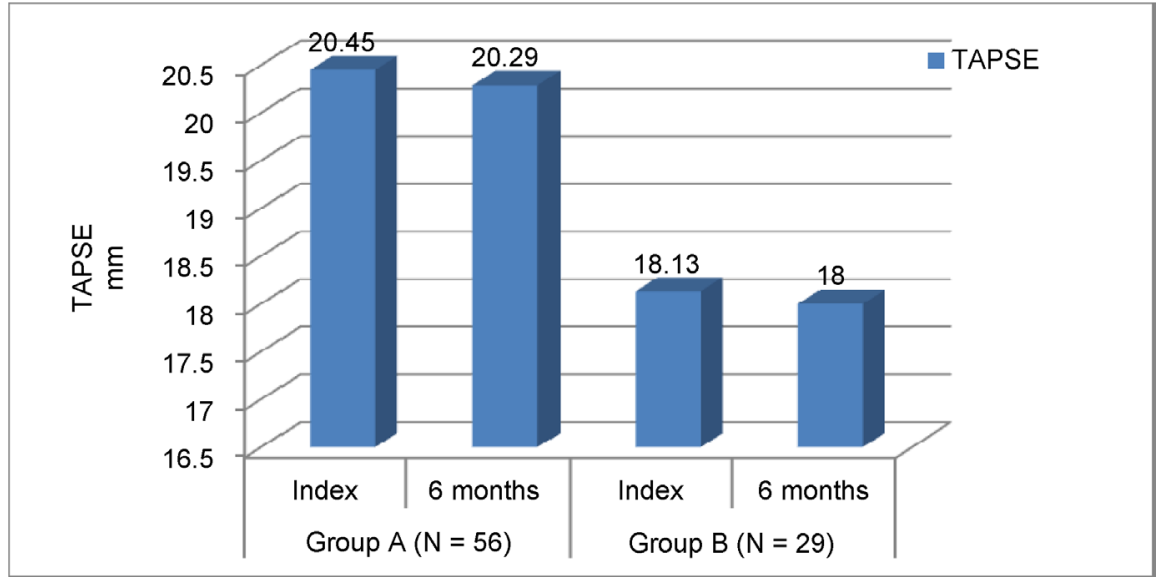

(b)

Figure 1. (a) Bar diagram showing echocardiographic RV function (E` septal\& E` lateral) parameters in group A and B during follow up. (b) Bar diagram showing echocardiographic RV function (TAPSE) parameter in group A and B during follow up. 
Table 3. Echocardiographic parameters in PAH patients with normal RV function and RV dysfunction at admission and follow up.

\begin{tabular}{lcccccr}
\hline \multicolumn{3}{c}{ Admission } & \multicolumn{3}{c}{ 6 Months } \\
\hline \multicolumn{3}{r}{ Normal RV function RV dysfunction } & P value Normal RV function RV & dysfunction P value \\
\hline E’ septal & 12.7 & 13.7 & NS & 12.6 & 6.2 & $<0.05$ \\
E' lateral & 15.9 & 10.2 & $<0.05$ & 16 & 8.9 & $<0.05$ \\
TAPSE & 20.6 & 13.6 & $<0.05$ & 20.6 & 13 & $<0.05$ \\
\hline
\end{tabular}

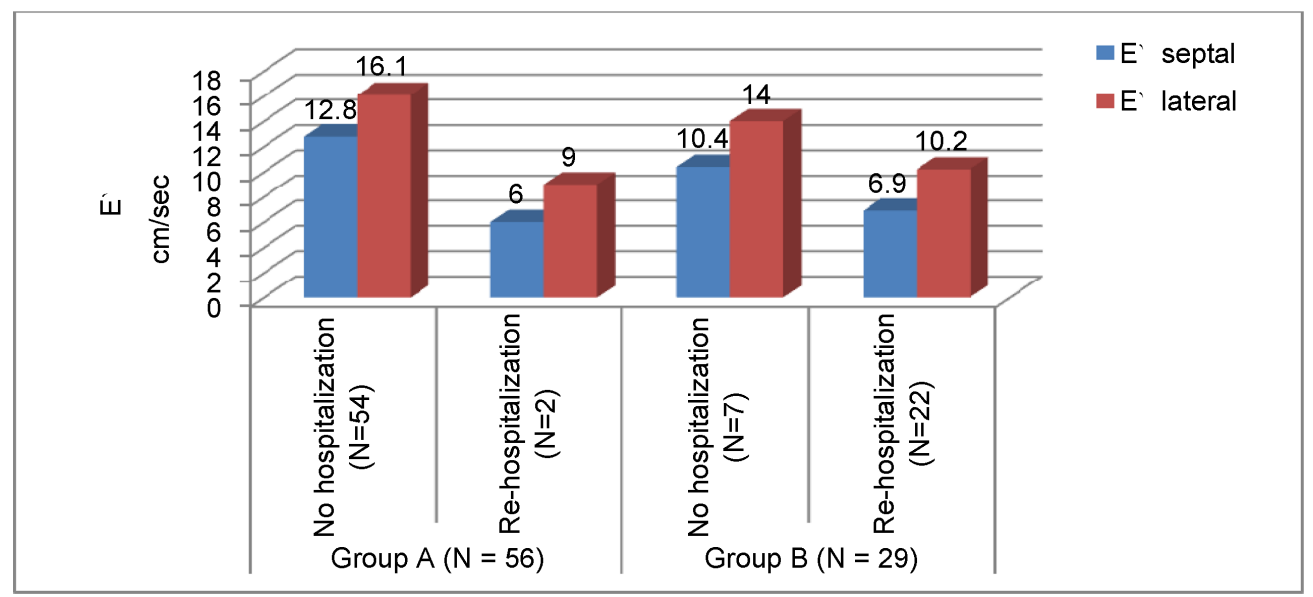

(a)

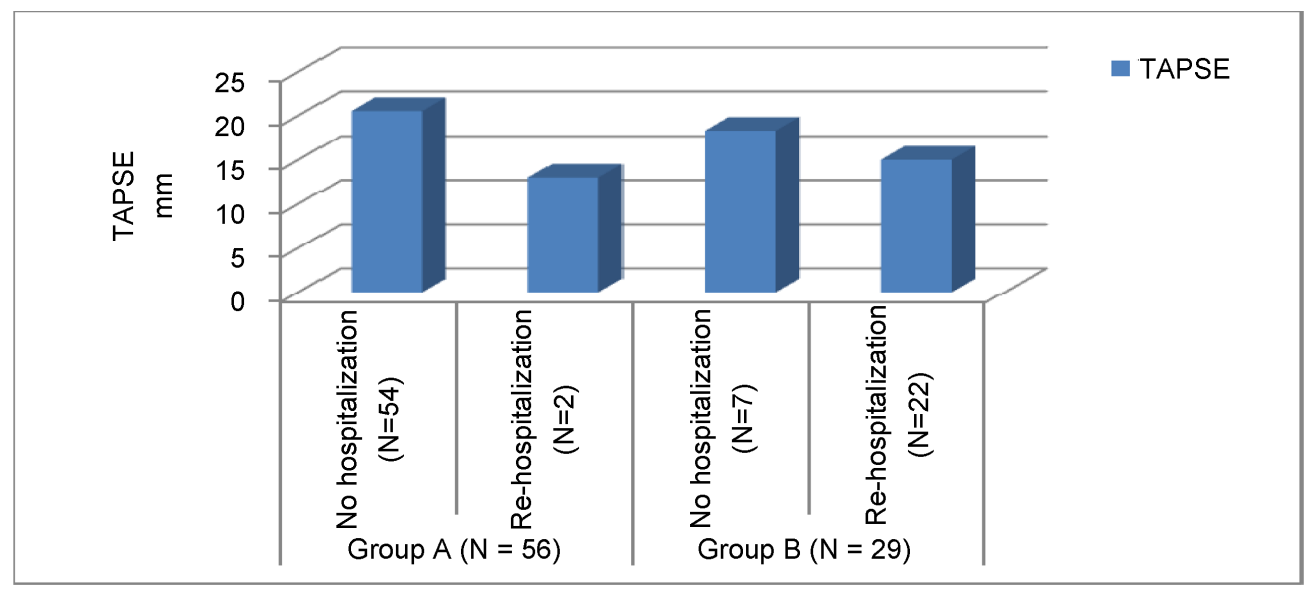

(b)

Figure 2. (a) Bar diagram showing comparison of RV echocardiographic parameters (E'septal and $E^{\prime}$ lateral) in re-hospitalized patients and non-hospitalized patients. (b) Bar diagram showing comparison of RV echocardiographic parameter (TAPSE) in re-hospitalized patients and non-hospitalized patients.

\section{Discussion}

Doppler tissue imaging, as a method of evaluating systolic and diastolic myocardial function, has been validated in numerous studies [2] [3] [4] [5]. For the right ventricle, the determination of velocities of tricuspid annular motion may provide a new tool for assessing systolic and diastolic function.

The principal findings of the present study can be summarised as follows. First, secondary cause of pulmonary hypertension was far more common than 
idiopathic PAH. Second, Grade I diastolic dysfunction was the commonest finding. Third, elevated pulmonary artery systolic pressure was inversely related with TAPSE and E' (TDI early diastolic annular velocity) at septal and tricuspid lateral annulus even without hemodynamically decompensated RV function which is in accordance to the previous literatures [6] [7].

Fourth, as postulated in previous studies [6] [8] [9] the present study showed that decrease in TDI early diastolic annular velocity and TAPSE may be a preceding step in the development of RV failure. Fifth, RV dysfunction patients had lower TAPSE and TDI early diastolic annular velocities. Sixth, lower TAPSE and TDI early diastolic annular velocities had more re-hospitalization.

The etiology of pulmonary hypertension has a varied spectrum extending from pulmonary disease, drugs, congenital heart disease and portal hypertension to HIV, collagen vascular disease and persistent pulmonary hypertension of newborn, etc. It also exists as a major component of many forms of cardiac and pulmonary disease. Estimates of disease prevalence are very difficult in the developing world because of geographic, economic, socio cultural, and ethnic diversity along with regional variations in healthcare infrastructure.

Traditionally, PAP is measured invasively by means of the pulmonary artery catheter (PAC), mostly in the intensive care setting. However, the use of PACs has declined in recent years as the use of PAC with all the attendant risks did not confer any benefit to management nor did it improve patient outcomes [10] [11]. The choice of a non-invasive, widely available, inexpensive, and accurate method still represents a problem. The accurate and most often applied methods, radionuclide ventriculography [12] [13] and magnetic resonance imaging [14] are time-consuming and relatively expensive methods, which cannot be used at the bedside. For this reasons, novel indices have been adopted for easier, highly reproducible and less variable evaluation of right ventricle function, such as the TAPSE and the TDI velocities of tricuspid valve. Tricuspid annular plane systolic excursion (TAPSE) is a simple echo-derived measure that correlates powerfully both with invasively measured hemodynamic parameters, right ventricular function and prognosis. A TAPSE of more than $1.8 \mathrm{~cm} / \mathrm{sec}$ indicates a good prognosis with 1 and 2 year survival rates of $94 \%$ and $88 \%$, respectively. [15] With each $1 \mathrm{~mm}$ decrease in TAPSE, the relative risk of mortality increases by $17 \%[15]$.

Tissue Doppler motion reflects the contraction and relaxation of longitudinal myocardial fibres in ventricles. It is a unique method of measuring systolic and diastolic velocities of motion of the annulae. TDI of both mitral (MA) and tricuspid annular (TA) velocities has been very useful in advancing our understanding of the systolic and diastolic properties of each respective ventricle. Huez et al., [16] using pulsed TDI and strain imaging, have shown that patients with severe $\mathrm{PH}$ have alterations in both systolic and diastolic function of the RV and evidence of LV diastolic dysfunction. Two-dimensional or M-mode echocardiographic measurement of excursions of the mitral or tricuspid annulus (in $\mathrm{mm}$ ) has been shown to reflect the systolic function of both ventricles [17] [18]. 
Kaul et al. [13] demonstrated a close correlation between the tricuspid annular plane systolic excursion, measured by means of 2-D echocardiography, and right ventricular ejection fraction, obtained by radionuclide angiography. Willenheimer et al. [19] and Karatasakis et al. [20] confirmed the relationship of both mitral and tricuspid annular excursion to mortality in patients with heart failure. As compared with the evaluation of annular excursions, the Doppler tissue imaging approach is quicker, simpler, and it enables both systolic and diastolic functional parameters to be measured simultaneously. Vinereanu et al. [21] by use of Doppler tissue echocardiography have demonstrated good reproducibility on acquiring and measuring tricuspid annular velocities.

While extensive works have been carried out using TDI for assessing of left ventricular systolic and diastolic functions, [22] only a limited number of studies have been performed on RV systolic and diastolic function [23] [24]. Caso et al., [25] by measuring the tissue Doppler velocity of the lateral tricuspid annulus, found that the relaxation time was proportional to the severity of PASP in COPD patients. Similarly, Ozdemir et al. [26] demonstrated that the RV myocardial performance index obtained by TDI correlated with PASP in patients with mitral stenosis. Saxena [27] demonstrated that the peak systolic tricuspid annular velocity obtained from TDI measurement is able to determine RV systolic function, regardless of pulmonary artery pressure and is strongly correlated with both functional area cure and TAPSE.

Hence it is evident that very few reports have been published on the impact of impaired right ventricular function on tricuspid annular velocities in diastole. Thus the aim of present study was to determine whether tricuspid annular velocities, as assessed by pulsed Doppler tissue imaging, could be used as index of right ventricular function in patients with pulmonary hypertension.

\section{Limitation}

The major limitation of present study is lack of healthy control group. Patients were enrolled from the same ethnic background. Duration of follow up is short in contrast to the natural history of secondary pulmonary hypertension. Present study also includes functional class which was more subjective. Finally, cardiac catheterization or radiological imagings (CMR) were not done to correlate with Doppler tissue imaging variables.

\section{Conclusions}

The present study demonstrates the utility of Doppler tissue imaging of tricuspid annular motion for the non-invasive evaluation of right ventricular systolic function.

Tissue Doppler imaging, early diastolic annular velocities (E') at septal and lateral tricuspid annulus and tricuspid annulus plain systolic excursion (TAPSE) is a simple, non-invasive, easily reproducible echocardiography tool to prognosticate the PAH patients. TAPSE, TDI E' septal and E' lateral tricuspid annular velocities in $\mathrm{PAH}$ patients are inversely related to elevated pulmonary artery 
systolic pressure, right ventricle function and rehospitalisation.

However, these findings need to be validated in larger numbers and ideally in a longitudinal study.

\section{References}

[1] McLaughlin, V.V., Presberg, K.W., Doyle, R.L., et al. (2004) Prognosis of Pulmonary Arterial Hypertension: ACCP Evidence-Based Clinical Practice Guidelines. Chest, 126, 78S-92S. https://doi.org/10.1378/chest.126.1_suppl.78S

[2] Oki, T., Tabata, T., Yamada, H., et al. (1997) Clinical Application of Pulsed Doppler Tissue Imaging for Assessing Abnormal Left Ventricular Relaxation. American Journal of Cardiology, 79, 921-928. https://doi.org/10.1016/S0002-9149(97)00015-5

[3] Derumeaux, G., Ovize, M., Loufoua, J., et al. (1998) Doppler Tissue Imaging Quantitates Regional Wall Motion during Myocardial Ischemia and Reperfusion. Circulation, 97, 1970-1977. https://doi.org/10.1161/01.CIR.97.19.1970

[4] Galiuto, L., Ignone, G. and DeMaria, A.N. (1998) Contraction and Relaxation Velocities of the Normal Left Ventricle Using Pulsed-Wave Doppler Echocardiography. American Journal of Cardiology, 81, 609-614. https://doi.org/10.1016/S0002-9149(97)00990-9

[5] García-Fernández, M.A., Azevedo, J., Moreno, M., et al. (1999) Regional Diastolic Function in Ischaemic Heart Disease Using Pulsed Wave Doppler Tissue Imaging. European Heart Journal, 20, 496-505. https://doi.org/10.1053/euhj.1998.1278

[6] Andreeva, Y., et al. (2010) Tissue Doppler Imaging in Detection of right Ventricular Systolic and Diastolic Function in Various Forms of Pulmonary Hypertension: PP.8.342. Journal of Hypertension, 28, e152. https://doi.org/10.1097/01.hjh.0000378666.32130.64

[7] Javed, U., et al. (2009) Correlation of Right Ventricular Tissue Doppler Imaging with Invasive Hemodynamics in Pulmonary Hypertension. Chest, 136, 31S-h1, 31Sh2. https://doi.org/10.1378/chest.136.4_meetingabstracts.31s-h

[8] López-Candales, A., et al. (2011) The Effect of Chronic Pulmonary Hypertension on Diastolic Annular Tissue Velocities: A Pilot Study. Retrospective Study, 341, 344349. https://doi.org/10.1097/maj.0b013e31820183b9

[9] Liao, P.N.J., et al. (2006) Tricuspid E/Em: A Novel Tool for Evaluation of Pediatric Patients with Pulmonary Hypertension. American Heart Association, Dallas, Abstract 114,3420 .

[10] Sandham, J.D., Hull, R.D., Brant, R.F., Knox, L., Pineo, G.F., Doig, C.J., et al. (2003) A Randomized, Controlled Trial of the Use of Pulmonary-Artery Catheters in HighRisk Surgical Patients. The New England Journal of Medicine, 348, 5-14. https://doi.org/10.1056/NEJMoa021108

[11] Connors Jr., A.F., Speroff, T., Dawson, N.V., Thomas, C., Harrell Jr., F.E., Wagner, D., et al. (1996) The Effectiveness of Right Heart Catheterization in the Initial Care of Critically Ill Patients. Journal of the American Medical Association, 276, 889-897. https://doi.org/10.1001/jama.1996.03540110043030

[12] Wilson, N.J., Neutze, J.M., Rutland, M.D. and Ramage, M.C. (1996) Transthoracic Echocardiography for Right Ventricular Function Late after the Mustard Operation. American Heart Journal, 131, 360-367. https://doi.org/10.1016/S0002-8703(96)90367-1

[13] Kaul, S., Tei, C., Hopkins, J.M. and Shah, P.M. (1984) Assessment of Right Ventricular Function Using Two-Dimensional Echocardiography. American Heart Journal, 107, 526-531. https://doi.org/10.1016/0002-8703(84)90095-4 
[14] Helbing, W.A., Bosch, H.G., Maliepaard, C.H., et al. (1995) Comparison of Echocardiographic Methods with Magnetic Resonance Imaging for Assessment of Right Ventricular Function in Children. American Journal of Cardiology, 76, 589-594. https://doi.org/10.1016/S0002-9149(99)80161-1

[15] Forfia, P.R., Fisher, M.R., Mathai, S.C., et al. (2006) Tricuspid Annular Displacement Predicts Survival in Pulmonary Hypertension, American Journal of Respiratory and Critical Care Medicine, 174, 1034-1041. https://doi.org/10.1164/rccm.200604-547OC

[16] Huez, S., Vachiéry, J.L., Unger, P., et al. (2007) Tissue Doppler Imaging Evaluation of Cardiac Adaptation to Severe Pulmonary Hypertension. American Journal of Cardiology, 100, 1473-1478. https://doi.org/10.1016/j.amjcard.2007.06.047

[17] Willenheimer, R., Israelsson, B., Cline, C., Rydberg, E., Broms, K. and Erhardt, L. (1999) Left Atrioventricular Plane Displacement Is Related to Both Systolic and Diastolic Left Ventricular Performance in Patients with Chronic Heart Failure. European Heart Journal, 20, 612-618. https://doi.org/10.1053/euhj.1998.1399

[18] Alam, M. and Samad, B.A. (1999) Detection of Exercise-Induced Reversible Right Ventricular Wall Motion Abnormalities Using Echocardiographic Determined Tricuspid Annular Motion. American Journal of Cardiology, 83, 103-105. https://doi.org/10.1016/S0002-9149(98)00789-9

[19] Willenheimer, R., Cline, C., Erhardt, L. and Israelsson, B. (1997) Left Ventricular Atrioventricular Plane Displacement: An Echocardiographic Technique for Rapid Assessment of Prognosis in Heart Failure. Heart, 78, 230-236. https://doi.org/10.1136/hrt.78.3.230

[20] Karatasakis, G.T., Karagounis, L.A., Kalyvas, P.A., et al. (1998) Prognostic Significance of Echocardiographically Estimated Right Ventricular Shortening in Advanced Heart Failure. American Journal of Cardiology, 82, 329-334. https://doi.org/10.1016/S0002-9149(98)00344-0

[21] Vinereanu, D., Khokhar, A. and Fraser, A.G. (1999) Reproducibility of Pulsed Wave Tissue Doppler Echocardiography. Journal of the American Society of Echocardiography, 12, 492-499. https://doi.org/10.1016/S0894-7317(99)70086-6

[22] Isaaz, K. (2002) Tissue Doppler Imaging for the Assessment of Left Ventricular Systolic and Diastolic Functions. Current Opinion in Cardiology, 17, 431-442. https://doi.org/10.1097/00001573-200209000-00001

[23] Meluzin, J., Spinarova, L., Bakala, J., Toman, J., Krejci, J., Hude, P., et al. (2001) Pulsed Doppler Tissue Imaging of the Velocity of Tricuspid Annular Systolic Motion. European Heart Journal, 22, 340-348. https://doi.org/10.1053/euhj.2000.2296

[24] Moustapha, A., Lim, M., Saikia, S., Kaushik, V., Kang, S.H. and Barasch, E. (2001) Interrogation of the Tricuspid Annulus by Doppler Tissue Imaging in Patients with Chronic Pulmonary Hypertension: Implication for the Assessment of Right Ventricular Systolic and Diastolic Function. Cardiology, 95, 101-104.

https://doi.org/10.1159/000047354

[25] Caso, P., Galderisi, M., Cicala, S., Cioppa, C., D’Andrea, A., Lagioia, G., et al. (2001) Association between Myocardial Right Ventricular Relaxation Time and Pulmonary Arterial Pressure in Chronic Obstructive Lung Disease: Analysis by Pulsed Doppler Tissue Imaging. Journal of the American Society of Echocardiography, 14, 970-977. https://doi.org/10.1067/mje.2001.115033

[26] Ozdemir, K., Altunkeser, B.B., Gok, H. and Cli, A. (2003) Does the Myocardial Performance Index Affect Pulmonary Artery Pressure in Patients with Mitral Stenosis? A Tissue Doppler Imaging Study. Echocardiography, 20, 249-256.

https://doi.org/10.1046/j.1540-8175.2003.03022.x 
[27] Saxena, N., Rajagopalan, N., Edelman, K., et al. (2006) Tricuspid Annular Systolic Velocity: A Useful Measurement in Determining Right Ventricular Systolic Function Regardless of Pulmonary Artery Pressures. Echocardiography, 23, 750-755.

https://doi.org/10.1111/j.1540-8175.2006.00305.x

Submit or recommend next manuscript to OALib Journal and we will provide best service for you:

- Publication frequency: Monthly

- 9 subject areas of science, technology and medicine

- Fair and rigorous peer-review system

- Fast publication process

- Article promotion in various social networking sites (LinkedIn, Facebook, Twitter, etc.)

- Maximum dissemination of your research work

Submit Your Paper Online: Click Here to Submit

Or Contact service@oalib.com 